\title{
A Case of Severe Ganciclovir-Induced Encephalopathy
}

\author{
Hikaru Sakamoto ${ }^{a}$ Makito Hirano ${ }^{a, c}$ Kazuhiro Nose ${ }^{b}$ Shuichi Ueno ${ }^{a}$ \\ Takashi Oki $^{b}$ Koichi Sugimoto $^{b}$ Tsukasa Nishioka $^{b}$ Susumu Kusunoki ${ }^{c}$ \\ Yusaku Nakamura ${ }^{a}$ \\ Departments of ${ }^{a}$ Neurology and ${ }^{b}$ Urology, Sakai Hospital Kinki University Faculty of \\ Medicine, Sakai, and 'Department of Neurology, Kinki University Faculty of Medicine, \\ Osakasayama, Japan
}

\section{Key Words}

Ganciclovir · Encephalopathy · Kidney transplantation · Dialysis · Cytomegalovirus enteritis

\begin{abstract}
Background: Ganciclovir, a drug against cytomegalovirus (CMV) infection, is generally well tolerated, but can cause neurotoxicity such as encephalopathy. Although ganciclovir-induced encephalopathy has been described in several reports, a literature search revealed that ganciclovir concentrations in the blood or cerebrospinal fluid were previously measured in only 3 patients with encephalopathy. Symptoms usually include confusion and disturbed consciousness, which mimic CMV encephalitis. Prompt and accurate diagnosis is thus sometimes difficult, and is derived solely from accumulated clinical information of definite cases, since ganciclovir concentrations, not routinely measured, become available after several days or a few weeks. Case Presentation: Here, we summarize clinical information of all patients with definite ganciclovir-induced encephalopathy including our own patient, who had severe symptoms, with the highest reported trough concentration of ganciclovir in the blood, and underwent therapeutic dialysis with complete recovery. Conclusion: Our summary of patients with definite encephalopathy could lead to prompt and accurate diagnoses.

(c) 2013 S. Karger AG, Basel
\end{abstract}

\section{Introduction}

Encephalopathy can be caused by neurotoxicity with prophylactically or therapeutically administered drugs such as acyclovir, ganciclovir, and their prodrugs, valacyclovir and 
valganciclovir [1]. The drugs are structurally similar nucleoside analogues, but their effects on neurons are poorly understood. Acyclovir-induced encephalopathy is more widely known than ganciclovir-induced encephalopathy, possibly because acyclovir is used against herpes virus infection, which is more common than cytomegalovirus (CMV) infection, for which ganciclovir is used. Ganciclovir was also reported to be effective against hepatitis B infection [2], but has rarely been used for this indication recently. Although ganciclovir-induced encephalopathy has been documented previously, a literature search revealed that ganciclovir concentrations in the blood or cerebrospinal fluid (CSF) have been reported in only 3 patients [1-3]. Previous reports on patients with such definite ganciclovir-induced encephalopathy have suggested that the trough concentration of ganciclovir in the blood is important [1]. Here, we summarize clinical information of patients with definite ganciclovirinduced encephalopathy including our own patient, who had severe symptoms, with the highest reported trough concentration of ganciclovir in the blood, and underwent therapeutic dialysis.

\section{Case Presentation}

A 55-year-old man started to receive hemodialysis because of diabetic renal failure 2 years previously. He underwent renal transplantation 1.5 years previously, and had been receiving immunosuppressants since then. Eight months after transplantation, the serum creatinine level increased to $4.4 \mathrm{mg} / \mathrm{dl}$. He had CMV enteritis with occult blood in the stool and an elevated CMV pp65 (C7-HRP) antigen level in blood mononuclear cells. Intravenous ganciclovir (150 mg/day) was administered for 11 days, followed by valganciclovir (450 $\mathrm{mg}$ /day). Because the enteritis was very severe, ganciclovir and valganciclovir were not reduced to maintenance doses, which are generally half of starting doses. Two days after starting valganciclovir, he had unsteady gait, but could walk unaided. On the next day, the patient needed assistance with walking. His consciousness was mildly disturbed (E3, V5, and M6 on the Glasgow Coma Scale). One day later, he became delirious intermittently. Two days later, he was found on the floor after falling, without major injuries. He was suspected to be irritated and exhausted because of severe enteritis. Nine days after starting valganciclovir, his level of consciousness worsened (E3, V3, and M5), and he could not receive oral drugs, including valganciclovir. Neurologists were consulted. Encephalitis was unlikely, since no meningeal signs or fever was noted; the cell count was normal ( 0.33 cells $/ \mu \mathrm{l})$ in the CSF, and the protein concentration marginally elevated (54 mg/dl). CMV, herpes simplex virus, varicella-zoster virus, and Epstein-Barr virus DNA was later found to be negative in the CSF. Ganciclovir-induced encephalopathy was suspected, and the drug was withdrawn. Because of the risk of further falls, hemodialysis using a VPS-15HA membrane, a vitamin E-coated polysulfone membrane (Asahi Kasei Kuraray Medical, Japan) was performed twice in 2 days. His consciousness improved considerably after the first session of dialysis (E3, V4, and M6) and was completely restored on the next morning after the second session (E4, V5, and M6). The trough levels of ganciclovir in the serum and CSF were retrospectively measured and are shown in table 1.

\section{Discussion}

We describe a patient with severe ganciclovir encephalopathy. Generally, ganciclovir is well tolerated, but caution is required in patients with renal impairment. Additionally, the 
severe symptoms in our patient may have been attributed to high doses of ganciclovir or valganciclovir for treatment of severe CMV enteritis.

The mechanism underlying ganciclovir encephalopathy remains largely unknown. Ganciclovir passes the blood-brain barrier [4]. Although the trough blood ganciclovir concentration in our patient was the highest reported to date, his CSF ganciclovir concentration was the second highest among the 4 patients reported to date in the literature. Such discrepancies between the CSF data and blood data may be explained by other factors, including penetration rates (how much ganciclovir passes through the blood-brain barrier), which are reported to vary among individuals [4]. However, CSF concentrations may not necessarily reflect the severity of encephalopathy. As an extreme example, 1 previous patient with an undetectable level of ganciclovir in the CSF (patient 2 in table 1) still had disturbed consciousness [1]. We speculate that the severe symptoms in our patient might have been attributed to peripheral nervous system involvement, which may be more sensitive to blood ganciclovir concentrations. Although definitive conclusions must await further studies, blood trough concentrations of ganciclovir may be more closely related to symptom severity than CSF concentrations.

Our findings show that dialysis was an effective treatment. Only withdrawal of the drug may lead to the complete resolution of symptoms. However, a fall, as observed in our patient, can cause devastating complications, an extended hospital stay, or both. In such patients, dialysis is a safe and effective treatment option. Dialysis also has a positive effect on the function of the transplanted kidney.

In summary, our experience suggests that therapeutic dialysis is a safe and effective treatment for encephalopathy as well as for a damaged transplanted kidney. The measurement of ganciclovir concentrations in the CSF may not be feasible for the management of encephalopathy in individual patients because it is not routinely performed, and because several days to several weeks are required for the results. Nonetheless, measurement of ganciclovir concentrations can play an important role in confirming the diagnosis and evaluating disease severity. We believe that accumulated knowledge on such patients with confirmed encephalopathy will lead to prompter and more accurate diagnoses.

\section{References}

1 Davis CL, Springmeyer S, Gmerek BJ: Central nervous system side effects of ganciclovir. N Engl J Med 1990;322:933-934.

2 Combarnous F, Fouque D, Chossegros P, Boulieu R, Laville M, Zech P: Neurologic side-effects of ganciclovir. Clin Nephrol 1994;42:279-280.

3 Peyriere H, Jeziorsky E, Jalabert A, Cociglio M, Benketira A, Blayac JP, Hansel S, Margueritte G, Hillaire-Buys $D$ : Neurotoxicity related to valganciclovir in a child with impaired renal function: usefulness of therapeutic drug monitoring. Ann Pharmacother 2006;40:143-146.

4 Fletcher C, Sawchuk R, Chinnock B, de Miranda P, Balfour HH Jr: Human pharmacokinetics of the antiviral drug DHPG. Clin Pharmacol Ther 1986;40:281-286. 


\section{Case Reports in Neurology}

\begin{tabular}{l|l}
\hline \multicolumn{2}{l}{ Case Rep Neurol 2013;5:183-186 } \\
\hline DOI: $10.1159 / 000355638$ & $\begin{array}{l}\text { C 2013 S. Karger AG, Basel } \\
\text { www.karger.com/crn }\end{array}$ \\
\hline
\end{tabular}

Sakamoto et al.: A Case of Severe Ganciclovir-Induced Encephalopathy

Table 1. Ganciclovir-induced encephalopathy

\begin{tabular}{|c|c|c|c|c|}
\hline Patient, $\mathrm{n}$ & 1 & 2 & 3 & 4 \\
\hline Age, years & 55 & n.d. & 73 & 13 \\
\hline$\overline{\operatorname{Sex}}$ & M & M & M & M \\
\hline Basal disease & DM, CRF & CRF & CRF & ALL \\
\hline Transplantation & Kidney & Kidney & - & $\begin{array}{l}\text { Hematopoietic } \\
\text { stem cell }\end{array}$ \\
\hline CMV infection & Enteritis & Hepatitis, duodenitis & $-($ Hepatitis B)* & $\begin{array}{l}\text { Retinitis, } \\
\text { interstitial } \\
\text { pneumonia }\end{array}$ \\
\hline Trough ganciclovir in blood, $\mu \mathrm{g} / \mathrm{ml}$ (after the last dose) & $\begin{array}{l}7.001(48 \mathrm{~h}) \\
0.215 \text { (after dialysis) }\end{array}$ & $2.0(12 \mathrm{~h})$ & $1.2(72 \mathrm{~h})$ & $\begin{array}{l}3.85(48 \mathrm{~h}) \\
1.97(72 \mathrm{~h}) \\
\end{array}$ \\
\hline Trough ganciclovir in CSF, $\mu \mathrm{g} / \mathrm{ml}$ (after the last dose) & $2.449(33 \mathrm{~h})$ & $0(12 \mathrm{~h})$ & $0.75(72 \mathrm{~h})$ & $2.6(48 \mathrm{~h})$ \\
\hline Ganciclovir (G) oral ganciclovir (V) dose & $\begin{array}{l}\text { G } 150 \mathrm{mg} \times 11 \text { days }+ \\
\mathrm{V} 450 \mathrm{mg} \times 8 \text { days }\end{array}$ & G $10 \mathrm{mg} / \mathrm{kg} \times 8$ days & G $1.25 \mathrm{mg} / \mathrm{kg} \times 5$ days & $\begin{array}{l}\mathrm{G} \times 14 \text { days }+ \\
\mathrm{V} 225 \mathrm{mg} \times \sim 14 \\
\text { days }\end{array}$ \\
\hline \multicolumn{5}{|l|}{ Symptoms } \\
\hline Unsteady gait & + & - & - & n.d. \\
\hline Dysarthria & + & - & + (aphasic) & n.d. \\
\hline Disturbed consciousness & + & + & + & + \\
\hline Other & Falls & & & Visual hallucination \\
\hline Creatinine clearance, $\mathrm{ml} / \mathrm{min}$ & 24.2 & $\begin{array}{l}\text { n.d. }(\text { serum creatinine }= \\
1.3 \mathrm{mg} / \mathrm{dl})\end{array}$ & n.d. & 20 \\
\hline \multicolumn{5}{|l|}{$\overline{\mathrm{CSF}}$} \\
\hline White cells $(/ \mu \mathrm{l})$ & 0.33 & n.d. & 0 & n.d. \\
\hline Protein, mg/dl & 54 & n.d. & Normal & n.d. \\
\hline$\overline{\mathrm{EEG}}$ & Slow waves & Normal & n.d. & Slow \\
\hline Imaging of brain & Normal MRI & Normal CT & $\begin{array}{l}\text { Left occipital, right } \\
\text { cerebellar ischemia on } \\
\text { CT** }\end{array}$ & n.d. \\
\hline $\begin{array}{l}\text { Withdrawal or decrease of ganciclovir } \\
\text { (days needed for recovery) }\end{array}$ & $\begin{array}{l}\text { Withdrawal } \\
\text { (no recovery after } \\
2 \text { days) }\end{array}$ & Decreased to half dose (3) & Withdrawal (5) & Withdrawal (2) \\
\hline Specific treatment (days needed for recovery) & Hemodialysis (2) & - & $* * *$ & - \\
\hline References & Present work & [1] & {$[2]$} & [3] \\
\hline
\end{tabular}

